\title{
Sixtieth Anniversary of the Journal
}

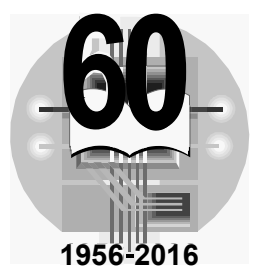

\section{Dear readers!}

Our journal turns sixty! The first issue of Journal "Automation" (since 1994 — "Problems of control and informatics") has come out due to efforts of group of Kiev scientists headed by A.G. Ivakhnenko at that time Corresponding member and then Academician of National Academy of Sciences of Ukraine who came to be its Editor in Chief for many years. Emergence of a new journal indicated to existence of Kiev school of specialists who quite confidently declared themselves in the field of theory and practice of control system construction.

Since then science has changed a lot in general and particularly the control science which widely extended the sphere of its applications. Our journal has also changed: from a printed organ of a comparatively small group of Kiev specialists in a control sphere it turned into the journal of initially narrow and then wide circle of specialists from different countries in the sphere of informatics and control. The journal has been appreciated abroad - since the 1960-s it has been translated into English and issued in USA, first by the firm SCRIPTA TECHNICA INC., A Wiley Company, and since 1996 by the firm BEGELL HOUSE INC.

Over the past 20-30 years there has been rapidly developed a comparatively new scientific trend the informatics that in not too distant future might "take in" the general control theory. Keeping up with time since 1994 the journal has been published under the title "Problems of control and informatics", and since 2009 it has been assigned the status "International scientific-technical journal "Problems of control and informatics".

The journal publishes works of our colleagues from many scientific centers of the former Union and now Russian Federation and other countries of CIS. Keeping up the tradition this issue also publishes the papers of our foreign colleagues who sent their papers for the anniversary issue of the journal that was highly appreciated by the editorial board. Since the number of papers entered the anniversary issues essentially exceeded the journal volume the number of papers was distributed between four issues No. 1-4.

Congratulations, dear authors and readers!

Editorial Board

ISSN 1064-2315

(C) 2016 by Begell House Inc. 